\title{
Palliative care for elderly South Asian immigrants: A systematic review
}

Jahan Shabnam¹, Helle Timm¹, Dorthe Susanne Nielsen² and Mette Raunkiær ${ }^{1}$

1. REHPA, the Danish Knowledge Centre for Rehabilitation and Palliative Care, the Region of Southern Denmark, the University of Southern Denmark

2. Migrant Health Clinic, Odense University Hospital. Center for Global Health, University of Southern Denmark. Health Sciences Research Center, University College Lillebaelt

\section{AIM OF THE STUDY}

To present results from a systematic literature review of available international evidence on experiences with and perspectives on palliative care among older South Asian immigrants, relatives and healthcare providers.

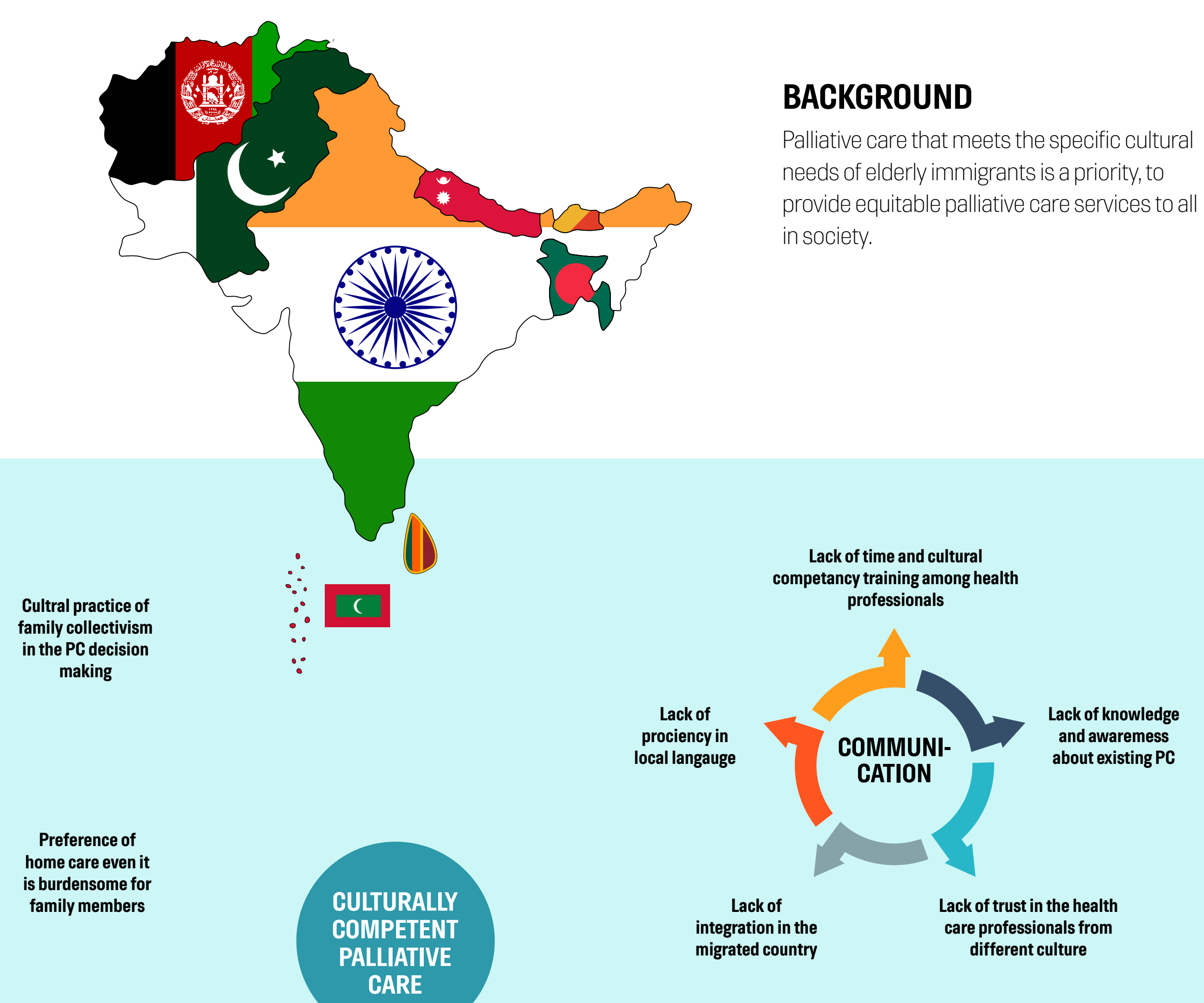

\section{METHOD}

Studies were searched in PubMed, EMBASE, CINAHL, and PsychINFO databases covering the period 2000 to 2018 in February 2018. Key words for search terms were palliative care, immigrants and South Asia. Thematic synthesis was used to analyses the data (articles).

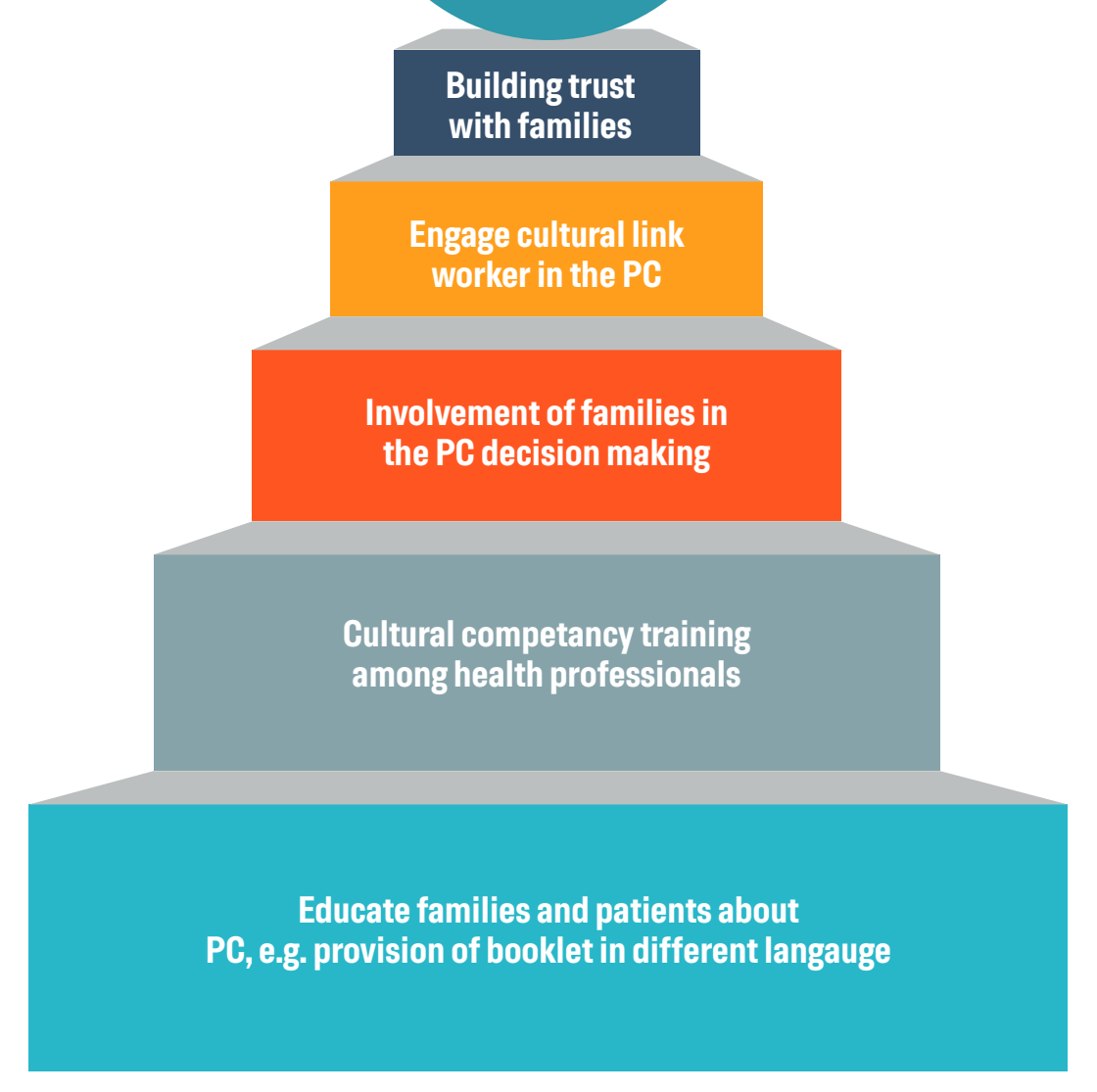

RECOMMENDATIONS

\section{CONCLUSION}

Considering the multi-ethnic nature of the world today, findings related to the importance of family involvement and culturally appropriate palliative care may be applicable to other immigrant populations beyond South Asians immigrants. 